\title{
Examining Proposed Changes to the Conceptualization of the Alexithymia Construct: The Way Forward Tilts to the Past
}

\author{
Graeme J. Taylor ${ }^{a}$ R. Michael Bagby ${ }^{a, b}$ \\ ${ }^{a}$ Department of Psychiatry, University of Toronto, Toronto, ON, Canada; bepartment of Psychology, University of \\ Toronto, Toronto, ON, Canada
}

Fifty years ago, Psychotherapy and Psychosomatics published an article by John Nemiah and Peter Sifneos [1] in which they reported some clinical observations on the mentation of a group of patients with "classic" psychosomatic diseases. This article, together with a book chapter published in the same year [2], heralded the soon to be introduced concept of alexithymia [3], which encompassed the cognitive characteristics that Nemiah and Sifneos had reported. The concept was not entirely new, which Nemiah and Sifneos readily acknowledged, and they noted that Ruesch [4] had described some of the same characteristics in the late 1940s; in addition, the cognitive style resembled the operational thinking (pensée opératoire) that Marty and de M'Uzan [5] had observed among somatically ill patients in France. As a theoretical concept, alexithymia quickly captured the interest of psychosomatic medicine specialists and was chosen as the main theme of the 11th European Conference on Psychosomatic Research held in Heidelberg in 1976 [6]. Though there were some critics of the concept, the majority of conference delegates agreed that alexithymia should be conceptualized as a hypothetical multifaceted construct that could be operationalized and evaluated empirically. On the final day of the conference, Sifneos [7] confident-

karger@karger.com www.karger.com/pps

Karger"

BOPEN ACCESS
(C) 2020 The Author(s)

Published by S. Karger AG, Basel

This is an Open Access article licensed under the Creative Commons Attribution-NonCommercial-4.0 International License (CC BY-NC) (http://www.karger.com/Services/OpenAccessLicense), applicable to the online version of the article only. Usage and distribution for commercial purposes requires written permission. ly predicted that "alexithymia is here to stay whether we like it or not and it is going to be with us for the rest of our lives" (p. 369). He recommended that a scientific approach be taken to further investigate the construct.

Half a century since the publication of Nemiah and Sifneos's initial report, it seems timely to evaluate Sifneos's prediction and recommendation, particularly because several alexithymia researchers have proposed various changes to the manner in which the construct was originally conceptualized and defined. These changes include adding an emotionalizing component to the alexithymia construct, removing the restricted imaginal activity facet, dividing alexithymia into categorically distinct subtypes, renaming severe degrees of alexithymia as "affective agnosia," reconceptualizing the construct within the framework of an attention-appraisal model, and theorizing alexithymia as a general deficit in interoception. These proposals raise a number of intriguing questions about the nature of alexithymia and present perspectives that we believe drift from the original observations of "psychosomatic" patients, which directly informed the theoretical parameters of the construct.

In this editorial, we consider these various perspectives and evaluate each of the proposed changes from both a 
theoretical perspective and an examination of findings from related empirical research. In each instance we explore how these different conceptualizations are mostly unmoored from the original conceptual formulations of Nemiah and Sifneos or merely recast them into an altered framework. We argue that any meaningful advancement in the field must remain firmly linked to those formulations and that the way forward must "tilt to the past." To achieve our goals, we first clarify what the label "construct" means in psychological science, and then briefly review Nemiah and Sifneos's description of the characteristics that compose the alexithymia construct.

\section{Psychological Constructs and the Original Conceptualization of Alexithymia}

In a seminal article outlining a framework for the testing of psychological theories and the instruments used to represent theoretical constructs, Loevinger [8] made a distinction between personality traits and psychological constructs - whereas traits exist in people and influence behavior, constructs are constructed in the minds of psychologists to represent their current best understanding of the corresponding trait. This is an important distinction because hypothetical constructs can be supported, refined, or replaced on the basis of accumulated empirical findings; traits, on the other hand, remain unchanged as they "exist prior to and independently of [attempts to measure them]" (p. 642) [8]. Contemporary experts in the field of psychometric theory and research make less of a distinction between traits and constructs; however, they emphasize that the existence of traits (such as neuroticism and extraversion) is inferred because doing so has utility for describing individuals and differences among people; in addition, investigating personality traits has potential for understanding and explaining aspects of human behavior $[9,10]$. The challenge is to develop tests to measure the construct in ways that validly reflect the hypothetical construct and relate to measures of other constructs in theoretically predictable ways [9]. And, as Strauss and Smith [10] indicate, each test of relations between measures reflects on the validity of both the measures and the theory driving the test.

In order to evaluate the validity of the alexithymia construct (or any hypothetical construct), it is essential to begin with a precise definition of the construct, because this determines how the construct is operationalized [10, 11]. A clear and precise description of the salient features that compose the alexithymia construct was published by
Nemiah et al. [12] shortly before the Heidelberg conference, and it is based entirely on a cluster of traits they observed in many of their "psychosomatic" patients; it was Sifneos's [3] impression that these traits are present also among drug addicts, alcoholics, and some personality disorder patients. The features included difficulty identifying feelings and finding words to describe feelings, difficulty distinguishing between subjective feelings and the bodily sensations that accompany emotions, difficulty distinguishing among different kinds of common affects, a paucity or absence of fantasies referable to drives and feelings, and a thought content characterized by a preoccupation with the minute details of external events. The last two features correspond to the concept of pensée opératoire. Nemiah et al. [12] noted also that some, but not all, alexithymic patients appear "stiff and wooden" in their manner and display few bodily gestures or facial expressions of emotion, and some may occasionally manifest brief outbursts of affective behavior such as weeping or intense rage, but without awareness of what prompted the behavior.

As emphasized by Strauss and Smith [10], construct validation is an ongoing process with simultaneous validation of both the theory and the instruments that are developed to measure the construct. This is particularly important for clinicians and researchers in the fields of psychotherapy and psychosomatics, for whom each construct they apply to patients, or investigate empirically, requires a shared common meaning, as well as evidence that the scores on the measures of the construct accurately reflect that meaning. Sifneos [3] and Apfel and Sifneos [13] developed two instruments to assess alexithymia: the interviewer-rated Beth Israel Hospital Psychosomatic Questionnaire (BIQ) and the self-report Schalling-Sifneos Personality Scale (SSPS). Although these measures were subsequently found to lack adequate psychometric properties [14], they included items that evaluated not only deficits in affect awareness and expression, but also fantasy activity and externally oriented thinking, indicating that Sifneos and Nemiah considered pensée opératoire a core component of the alexithymia construct. In contrast to Sifneos, who was not familiar with methods of psychological test construction, a team of Canadian researchers followed standard psychometric guidelines and developed a self-report scale: the Toronto Alexithymia Scale (TAS) [15]; this scale has 26 items and 4 factor scales that reflect the salient features of the construct. After some shortcomings of this scale had been identified, Bagby, Parker, and Taylor $[16,17]$ sought to address the limitations and developed a revised 20 -item version, which 
demonstrated improved psychometric properties. The 20 -item Toronto Alexithymia Scale (TAS-20) [18] is composed of 3 factor scales that assess difficulty identifying feelings (DIF), difficulty describing feelings to others (DDF), and externally oriented thinking (EOT) [16]; there is evidence that the EOT factor scale also indirectly assesses fantasizing activity $[17,18]$. The Canadian group also developed the Toronto Structured Interview for Alexithymia (TSIA) with 4 factor scales (DIF, DDF, EOT, and imaginal processes [IMP]) [19] and designed a modified version of the BIQ in an effort to improve this instrument [20]. Empirical studies with these self-report, structured interview and observer-rated instruments have yielded findings that not only support their validity, but also the validity of the alexithymia construct as it was originally conceptualized $[18,20,21]$. For example, consistent with theoretical predictions and with the clinical observations of psychotherapists, the TAS-20 correlates negatively with measures of psychological mindedness, affective orientation, need for cognition, and emotional intelligence [22]. Furthermore, studies examining relations between the TAS-20 and measures of the Five-Factor Model of Personality (FFM) and Cloninger's Psychobiological Model of Personality found that the alexithymia construct does not correspond to any domain or lower-order traits within these models of personality, but is a unique trait, best explained by a complex mixture of traits across the different domains, dimensions, and traits of the FFM and Cloninger's model $[23,24]$.

In the next sections, we describe and evaluate the various proposed changes to the alexithymia construct. How some of the proposals modify the measurement of alexithymia is also discussed.

\section{Emotionalizing}

During the latter half of the 1990s, a team of Dutch researchers extended the definition of the alexithymia construct by adding a fifth component, which they initially named "emotional excitability" [25], and later referred to as "reduced experiencing of emotional feelings" [26, p. 415] or an "inability to experience emotional feelings" $[27$, p. 243]. This broader conceptualization of the alexithymia construct was operationalized in the development of the 40-item self-report Bermond-Vorst Alexithymia Questionnaire (BVAQ) [26], which is composed of 5 subscales: Identifying (IDEN), Verbalizing (VERB), Analyzing (ANAL), Fantasizing (FAN), and Emotionalizing (EMO); the first 3 subscales assess the same components

The Alexithymia Construct of the alexithymia construct as do the DIF, DDF, and EOT subscales of the TAS-20. The EMO subscale, as defined by Vorst and Bermond [26], assesses "the degree to which someone is emotionally aroused by emotion inducing events" (p. 417). We think this is a theoretically unsupportable modification to the alexithymia construct, since we believe it diverges from its original conceptualization as formulated by Sifneos and Nemiah. There is an important difference between reduced experiencing of emotional feelings and whether one is emotionally aroused by emotion-inducing events. This difference is evident in the distinction that Nemiah et al. [12] and Sifneos [28] made between emotions and feelings: they defined the former as the visceral and motor-expressive components of affects, and the latter as the subjective, cognitive-experiential component. As Damasio [29] writes, "Emotions play out in the theater of the body. Feelings play out in the theater of the mind" (p. 28). Because Vorst and Bermond [26] overlook this distinction, clinicians and researchers are left uncertain as to whether the EMO subscale of the BVAQ is intended to assess differences in physiological arousal or differences in awareness of feelings [30]. Sifneos and Nemiah made clear that although alexithymic individuals experience emotions in response to emotional stimuli, they have difficulty labeling and describing subjective feelings; they may report being nervous, sad, or angry, but when asked, they are unable to elaborate further on what they are experiencing [12]. In our view, this deficit in the ability to know what one is feeling and to find words to describe the feeling is represented by the DIF and DDF components of the alexithymia construct.

Results from several different empirical investigations have yielded little support for the proposed emotionalizing facet. Most factor analytic studies of the BVAQ support a 5-factor model with 2 higher-order factors: a Cognitive factor (composed of the IDEN and VERB factors), and an Affective factor (composed of the FAN and EMO factors); the ANAL factor, which assesses the ability to analyze or reflect on one's emotions, usually loads on both higher-order factors, but is considered part of the Cognitive factor [26, 31]. Contrary to the widely accepted theoretical model of alexithymia, which specifies that the facets of the construct are interrelated, the Cognitive and Affective factors of the BVAQ are largely uncorrelated [27]. Indeed, Bermond et al. [27] advise against using BVAQ total scores. Furthermore, as Preece et al. [32] point out, the items on the EMO subscale do not reflect a distinction between positive reactivity and negative reactivity - which is important, as these dimensions of reac- 
tivity correlate negatively with each other - and the content of 3 EMO subscale items appear to assess empathy rather than emotional reactivity. Preece and his team of Australian researchers conducted studies in which they replaced the EMO subscale with the Perth Emotional Reactivity Scale [33] and found no support for this proposed fifth component of the alexithymia construct [32, 34]. In other research, our team used the method of network analysis to examine the topology of alexithymia with BVAQ data from a large heterogeneous multilanguage sample [35]. The results also failed to support emotionalizing as a distinct component of the construct; moreover, contrary to the assumption of Bermond et al. [31] that emotionalizing and fantasizing are closely related and together form the higher-order Affective factor of the BVAQ, the nodes representing these two facets were not connected in the facet-level analysis of the network. In sum, the inclusion of an emotionalizing component (defined as reduced emotional arousal in response to emotional stimuli) as a part of alexithymia is theoretically inconsistent with the origination of the construct. Equally important is that two independent teams of researchers using very different statistical analytic methods failed to provide empirical evidence that emotionalizing is a constituent component of the alexithymia construct.

\section{Subtypes of Alexithymia}

Although Nemiah and Sifneos were not entirely clear as to whether they regarded alexithymia as a categorical or dimensional construct, they never conceptualized different types or kinds of alexithymia. Nevertheless, based on some assumptions and findings from various studies reporting associations between cerebral lesions or malfunctions and altered emotional experience, Bermond [36] hypothesized that measurement studies would identify two subtypes of alexithymia. Bermond and his colleagues later proposed two additional subtypes [26, 31]. They supported their proposal with inferences drawn from the higher-order factor structure of the BVAQ, which has been replicated in many, but not all, higherorder factor analytic studies. Because the higher-order Cognitive and Affective factors are only weakly correlated, Bermond et al. [31] suggested that they represent two independent dimensions of alexithymia. According to the proposal, high scores on both factors correspond to Type I alexithymia; high scores on the Cognitive factor and low scores on the Affective factor correspond to Type II alexithymia; low scores on the Cognitive factor and high scores on the Affective factor correspond to Type III alexithymia; and low scores on both factors correspond to Lexithymia (i.e., an absence of alexithymia) [37]. As far as we are aware, Bermond and colleagues have not published any case examples from clinical settings that illustrate the features of Type II and III alexithymia. It therefore seems that these types are based solely on the results of factor analytic studies derived from variable-based patterns of covariation, which may not match to clinically observable trait characteristics in patient samples. The exclusive reliance of the formation of types on mere statistical manipulation is far removed from the careful clinical observation of somatically ill patients from which the alexithymia construct emerged.

Notwithstanding the lack of clinical observations of these types, the idea that alexithymia is a taxon or "type" that can be subdivided further into subtypes is inconsistent with empirical findings from taxometric studies with both the TAS-20 and the TSIA, which have yielded strong support for a dimensional conceptualization of the alexithymia construct [38-40]. Other studies that used the methods of cluster analysis and latent profile analysis have also failed to identify subgroups of individual or profile types that correspond to the purported subtypes [41-43]. Indeed, consistent with the dimensional view of the alexithymia construct, most of the profiles that emerged in the two studies that used latent profile analysis seemed to correspond to individuals with differing levels of alexithymia severity rather than categorical types.

\section{The Reduced Fantasy Facet of Alexithymia}

In recent years, Preece et al. $[32,34]$ have argued for removing the constricted IMP component of alexithymia and redefining the construct as composed of only 3 facets: DIF, DDF, and EOT. The proposal was based initially on empirical findings, without any a priori theoretical rationale. This team of Australian researchers note that the TAS-20 does not include items for assessing fantasizing and other imaginal activity, but they fail to report that the items from the original TAS, together with additional items written to assess this facet, were eliminated during revision of the scale because of low item-total correlations and/or high correlations with a measure of social desirability [16]. Instead, they mistakenly report that the reason why these items were removed was only because the daydreaming factor of the TAS was found to be uncorrelated or negatively correlated with the DIF and DDF factors. Although Preece et al. [32] acknowledge that the 
TSIA includes a subscale for assessing the IMP component of the construct, they refer to studies in which this subscale did not correlate significantly with the TAS-20 total score, and suggest that positive correlations of IMP with the other subscales of the TSIA may primarily be due to shared method variance. Preece et al. [34] subsequently conducted an exploratory factor analysis of data collected with a battery of tests, including three different selfreport measures of imaginal activity. Whereas scores on the DIF, DDF, and EOT subscales of the TAS-20 and the Perth Alexithymia Questionnaire (PAQ) [44] loaded together on an alexithymia factor, none of the scores from the three measures of imaginal activity loaded on this factor. Preece et al. [32, 34] conclude that like emotional reactivity, the available data suggest that impaired IMP is statistically better conceptualized as a separate construct that may correlate with alexithymia but is not a core component of the construct.

In our own research, we conducted a network analysis of TSIA data from a large heterogeneous language sample in which the items assessing IMP were found to be connected to the network primarily through the items assessing externally oriented thinking [45]. Although this finding suggests that IMP is a more peripheral component of the construct, it is consistent with findings from other studies in which the EOT subscale of the TAS-20 correlated negatively with measures of fantasizing $[18,23]$. These correlations suggest that in addition to externally oriented thinking, the EOT subscale indirectly assesses IMP. Moreover, consistent with the theoretical formulation by Nemiah et al. [12], the EOT and IMP factors of the TSIA together form a higher-order domain scale, which was labeled Operative Thinking, whereas the DIF and DDF factors together form a higher-order Affect Awareness domain scale [19]. In contrast to the Cognitive and Affective factor scales of the BVAQ, the domain scales of the TSIA are strongly correlated. In our view, impaired IMP is an important aspect of pensée opératoire, but an aspect that is difficult to assess with self-report and structured interview measures of alexithymia. It may be more adequately assessed with projective/performance measures, such as the Rorschach Reality-Fantasy Index, on which higher scores reflect a reality-oriented thinking style and an impoverished capacity for imaginal activity. This instrument was found to correlate positively and strongly with the EOT subscale of the TAS-20, and also with the DIF and DDF subscales, in a sample of patients with inflammatory bowel disease [46]. Further empirical studies using this Rorschach Index are needed, as well as dialogue and collaboration with members of the Paris
School of Psychosomatics, who are accustomed to recognizing pensée opératoire in their patients.

\section{Affective Agnosia}

The concept of affective agnosia was introduced by Lane et al. [47], who describe it as a new type of agnosia "that involves a deficit in the ability to mentally represent the meaning of emotional responses" (p. 595). They propose that "affective agnosia" may be a better label for the construct described by Nemiah and Sifneos because the term "alexithymia," when taken literally, means lack of words for emotion, which implies an "affective anomia." Using a developmental/continuum model in which emotions acquire increasing complexity of mental representation, Lane and colleagues place affective agnosia at the most severe end of impairment and suggest the term "affective anomia" for lesser degrees of impairment at the other end of the continuum. They refer to these as agnosia and anomia versions or subtypes of alexithymia.

It was the impression of Lane et al. [47] that a conceptual distinction between anomia and agnosia had not previously been considered in relation to alexithymia. However, as we outlined in a commentary on their article [48], Sifneos $[49,50]$ had initially contemplated the concept of "emotional agnosia" and later the idea of a "feeling aphasia." If Sifneos had combined these ideas, he might have described alexithymia as an "affective agnostic aphasia" (i.e., a failure to recognize and find words to describe emotions). Contrary also to the view of Lane et al. [47] that the concept of affective agnosia would advance the theory and measurement of alexithymia, we showed from a review of the alexithymia literature that impairment in the mental representation of emotions has been a central aspect of alexithymia theory since the concept was introduced, and has guided the development of measures of the construct. In our view, the concept of affective agnosia links well with the theory of levels of emotional awareness by Lane and Schwartz [51] and maps onto a hierarchical model of neural substrates of emotional experience, but it does not encompass the pensée opératoire component of the alexithymia construct. In addition, identifying agnosia and anomia categorical subtypes of alexithymia is inconsistent with the dimensional nature of the construct [48].

Another concern with applying the label "affective agnosia" to the alexithymia construct is that it is traditionally associated with cerebral lesions. Indeed, contrary to the assumption of Lane et al. [47] that the concept is new, 
it has been used by neurologists since at least the mid1970s to refer to patients with organic brain disorders who manifest an "auditory affective agnosia" (impairment in the comprehension of affective speech) or a "prosopo-affective agnosia" (an impairment of facial affect recognition without impairment in the recognition of facial features) [52, 53]. Although Lane et al. [47] proposed a model involving dysfunctional neural circuits that may underlie affective agnosia, and several studies have reported alexithymia in patients with neurological disease [54], there is no evidence that cerebral lesions are the primary cause of alexithymia. We agree that the neural correlates of alexithymia and dysfunctions within them are likely to vary with different degrees of severity of the construct. And, as we have always argued, multiple methods of measuring the construct are needed, especially to identify individuals with severe degrees of alexithymia.

\section{The Attention-Appraisal Model of Alexithymia}

In the discussion of results of an exploratory factor analysis of a battery of psychometric measures, Preece et al. [34] argue that the proposed change to a 3-component conceptualization (i.e., removing the reduced fantasy component) of the alexithymia construct is not driven purely by statistical findings. They argue that a theoretical rationale for the change is provided by an attention-appraisal model of alexithymia in which DIF, DDF, and EOT are conceptualized as deficits specific to emotion processing and are therefore expected to cohere as parts of a common construct [32]. In this model, which is based within Gross's [55] process model of emotion regulation (including a situation-attention-appraisal-response sequence whereby an emotional stimulus is evaluated for its meaning), EOT is conceptualized as difficulty focusing attention on the emotional response to a stimulus; DIF and DDF are conceptualized as difficulties in appraising what the emotional response is and what it means. Preece et al. [32] acknowledge that their understanding of EOT as a failure to properly focus attention on one's emotions differs from Nemiah and Sifneos's $[1,2,12]$ observation that alexithymic individuals' thinking is focused excessively on external objects or events; however, they regard their redefinition of EOT as merely "a subtle shift in emphasis" (p. 344). Preece et al. [32] suggest that difficulties at the attention and appraisal stages of emotion valuation may occur in individuals who have deficits in the mental representation of emotions; they refer to this as "ability deficit alexithymia." They suggest also that some difficulties at the attention and appraisal stages may occur when individuals avoid properly focusing their attention on the emotional response or avoid linking available input information about the emotional response to their emotion schemas; they refer to this as "avoidance alexithymia" and consider it an emotion regulation strategy. We agree that a theoretical understanding of alexithymia involves both deficits in affect development and defensive avoidance to regulate distressing affects [56], but see no need to propose "ability deficit" and "avoidance" types of alexithymia, which, like the distinction proposed by Lane et al. [47], muddles categorical and dimensional conceptualizations of the alexithymia construct.

For clinicians and researchers who want to work within the framework of the attention-appraisal model of alexithymia, Preece et al. [44] developed the self-report PAQ. Like the TAS-20, the PAQ has 3 subscales that assess DIF, DDF, and EOT. One difference between the two scales is that the DIF and DDF subscales of the PAQ contain items that pertain to positive affect as well as items that pertain to negative affect. And whereas the EOT items on the TAS-20 were written to assess operatory thinking (which includes inattention to affects), all EOT items on the PAQ were written to assess attention to emotions. Notwithstanding these differences, the total scale scores of the PAQ and the TAS-20 have been shown to correlate highly, as do also the scores on the subscales designed to assess DIF, DDF, and EOT [57]. As Preece and colleagues suggest, the PAQ may provide more nuanced information than the TAS-20; for example, PAQ subscale scores indicating whether a patient has more difficulty identifying feelings of a particular valence may help guide psychotherapists who are treating alexithymic patients. There are clinical reports and evidence from previous empirical studies that alexithymia is associated with a low tendency to experience positive affect $[20,23]$, and also preliminary evidence that the lack of expression of positive emotion by the patient may evoke a negative reaction in the therapist, which can result in poorer outcome [58]. On the basis of feedback mechanisms within emotion regulation systems, whereby interests generate positive emotions and reduce negative emotions, Taylor [59] suggested that an important focus of psychotherapy should lie on enhancing the patient's capacity for fantasy and other imaginal activity and on fostering the development of interests and positive emotions (i.e., aspects of openness to experience).

There is some merit to the attention-appraisal model of alexithymia: it conceptualizes alexithymic difficulties 
within the framework of a developmental level of emotion schemas proposed by Lane and Schwartz [51], integrates deficit and defense aspects of the construct, and links alexithymia with disturbances in affect regulation. An important concern, however, is that the removal of the impaired IMP component from the definition of the construct, and the reconceptualization of EOT solely as a tendency to not focus attention on one's own emotions, essentially rejects the concept of pensée opératoire, which Nemiah and Sifneos $[2,12]$ considered a major component of alexithymia. It is important to recall that Marty and de M'Uzan [5] described operatory thinking as a conscious and completely original mode of thinking that appears to lack any intrinsic connection with a discernable level of fantasy activity, and duplicates and illustrates action, sometimes preceding it, sometimes following it. Marty and de M'Uzan noted also that people with this operative thinking style recall few dreams, and when they do, the dreams involve actions that are always connected closely with an existing reality. Smadja [60], a contemporary member of the Paris School of Psychosomatics, similarly defines operatory thinking as "a mode of thinking which is present, factual and without links to a phantasizing or symbolizing activity" (p. 227). In describing the features of alexithymia, Nemiah et al. [12] indicated that "the pensée opératoire consists of two basic elements: (1) a paucity or absence of fantasy referable to drives and feelings, and (2) a thought content characterized by a preoccupation with the minute details of external events, which may include their somatic dysfunctions and the reactions of others to their illness" (p. 433). Moreover, Nemiah [61] stated that in addition to the difficulty alexithymic patients have in describing their feelings or differentiating between them, they manifest "an absence of the capacity to produce fantasies with the result that the thought content of such patients is restricted to a preoccupation with external objects, people, and environmental events" (p. 127). That is, Nemiah seemed to attribute EOT to the absence of imaginal activity rather than to a failure to attend to emotions, or to an avoidance of emotions, in his conceptualization of alexithymia. It is noteworthy that an international group of investigators included lack of a rich fantasy life and externally oriented thinking among the criteria for identifying alexithymia when they developed the Diagnostic Criteria for Psychosomatic Research (DCPR), a structured interview method for assessing alexithymia and many other psychosomatic syndromes [62]; these criteria were retained in the recently updated version of the instrument [63]. In our opinion, the redefinition of EOT by Preece et al. [32] is more than a subtle shift in emphasis. Indeed, there is evidence that EOT assessed with the TAS-20, like the other facets of the alexithymia construct, is inversely related to the broader constructs of psychological mindedness, need for cognition, openness to experience, and emotional intelligence, most of which include attentiveness to inner feelings $[18,22]$; these findings indicate that the TAS-20 with its 3 factor scales has excellent nomothetic span [10]. Relations between the PAQ and these broader constructs have yet to been reported.

\section{Alexithymia as a Deficit in Interoceptive Awareness}

In recent articles, Brewer et al. $[64,65]$ proposed that alexithymia should be thought of as a general impairment or deficit of interoception. These British researchers acknowledge that the original definition of alexithymia by Nemiah et al. [12] included difficulties distinguishing emotions from other bodily sensations; however, they seem to have overlooked other relevant background history and early empirical work linking interoception with alexithymia. As indicated by Taylor [66] more than 30 years ago, an interoceptive deficit was described by Hilda Bruch in 1973, the same year that Sifneos [3] introduced the term "alexithymia." Bruch [67] reported that patients with eating disorders are often confused about the nature of their affective states and commonly misperceive internal experiences, particularly those related to hunger and satiety. In her opinion, this "interoceptive confusion" is a consequence of consistent poor attunement between the innate needs of the developing child and the responses of the caregivers in the environment. Bruch [68] recommended that therapeutic interventions should be directed toward helping patients to become more aware of feelings originating within themselves and to learn to discriminate between various bodily sensations and emotional states. Garfinkel and Garner [69] attributed the characteristics described by Bruch to a deficit in interoceptive awareness, a construct that Garner et al. [70] operationalized in the Interoceptive Awareness (IA) subscale of the Eating Disorder Inventory (EDI) [71]. Recognizing the theoretical overlap of deficits in interoception with the alexithymia construct, Taylor et al. [15] selected 4 items from the IA subscale of the EDI for inclusion in the pool of items from which the TAS was developed. Because these 4 items specifically assessed difficulty identifying affective states, 2 additional items ("I am often puzzled by sensations in my body" and "I have physical sensations that even doctors don't understand") were written to cap- 
ture difficulty identifying and appreciating the meaning of bodily sensations. All 6 items loaded significantly on the DIF factor scale of the TAS and were retained when the scale was revised to form the TAS-20 [16]. In a sample of patients with anorexia nervosa, and after removal of the 4 items on the TAS-20 that were derived from the IA subscale, the two scales correlated significantly $(r=0.42$, $p<0.01)^{1}[72]$.

As noted recently by Trevisan et al. [73], the term interoceptive awareness is quite broad and over the years has been inconsistently defined and conceptualized. For the purpose of investigating psychosomatic functions, Cameron [74] defines interoception as the perception of afferent information that arises from anywhere and everywhere in the body including the skin and muscles as well as the visceral organs. Since most interoceptive processes operate outside of conscious awareness, measurement is limited to those processes that are available to conscious report and is therefore quite challenging [73]. Moreover, researchers now conceptualize interoception as a multifaceted construct and attempt to measure separate components. These include (1) interoceptive accuracy (IAcc), which refers to an individual's ability to perceive accurately signals from within the body, such as one's heart rate; (2) interoceptive sensibility (IS), which refers to an individual's subjective belief and confidence they are accurate at perceiving bodily states; and (3) interoceptive awareness (IA), which is defined as a metacognitive awareness of interoceptive accuracy (i.e., the extent to which subjective interoceptive sensibility accurately reflects one's objective interoceptive sensitivity) $[65,75]$.

The suggestion by Brewer et al. [65] that alexithymia be conceptualized as a general failure of interoception, rather than being associated specifically with affective impairment, stemmed partly from a study which found that higher TAS-20 scores in both healthy individuals and individuals who reported having a psychiatric diagnosis were related to a greater degree of perceived similarity between affective and nonaffective interoceptive states. In that study, IS was assessed with a self-report instrument that evaluates the extent to which individuals experience emotions and nonaffective states as similar to each other. In an earlier study, Herbert et al. [76] found that IAcc measured objectively by a heartbeat detection task, even after controlling for depression, significantly predicted TAS-20 total scores and scores on all 3 factor scales in a

\footnotetext{
1 Higher scores on the IA subscale of the EDI indicate greater interoceptive impairment.
}

sample of healthy men and women. This finding was challenged by a later study which found no significant association between heartbeat tracking accuracy and TAS20 scores across separate healthy adult and autistic spectrum disorder samples [77]. More recently, Trevisan et al. [73] conducted a meta-analysis of 44 studies that empirically examined the relationship between alexithymia and components of interoceptive awareness. Although alexithymia had a small negative correlation with interoceptive awareness across 66 separate samples $(r=-0.162, p=$ 0.001 ), the strength and directionality of this association was heavily influenced by the facet of the construct measured, and by whether it was measured with objective or self-report measures. In addition, poorer interoceptive awareness was much more strongly related to alexithymia in clinical samples, especially patients with eating disorders or autistic spectrum disorder, than in healthy samples.

Although from a theoretical perspective, impaired interoception may contribute to the etiology of alexithymia, given the uncertainties around the measurement of interoception and the inconsistent findings in the empirical literature, we consider it premature to characterize alexithymia as a general deficit in interoception. A question for future research is whether the interoceptive deficits in alexithymia include a failure to detect physiological states (i.e., IAcc) or are limited to difficulty interpreting emotional and other physiological sensations accurately (i.e., IS).

\section{Conclusions}

The theoretical issues and empirical studies reviewed in this article confirm Sifneos's [7] prediction that alexithymia would be here to stay, even though there have been several proposed changes to the conceptualization and/or measurement of the construct. Some of the proposed changes are either based on empirical considerations without adequate theoretical justification, or are not supported by new clinical observations or linked to all of the characteristics observed by Nemiah and Sifneos [1-3] and included in the original definition of the alexithymia construct. There is minimal theoretical or empirical support for adding an emotionalizing component to the construct or for identifying subtypes of alexithymia. The attention-appraisal model of alexithymia and the development of the PAQ present an excellent interplay between theory and empiricism, and the model "aligns alexithymia theory with recent advances in the broader field 
of emotion regulation" [32, p. 341]. However, the exclusion of the IMP component from the model and from the PAQ markedly changes the original conceptualization of the alexithymia construct. We question whether the construct should retain the label "alexithymia" if it no longer includes the pensée opératoire component. There are undoubtedly different interpretations of EOT and difficulties in developing valid measures of operatory thinking. Regrettably, French-speaking psychoanalysts who are followers of Marty and continue to write about pensée opératoire have not yet operationalized and evaluated the phenomenon empirically. There are no sound reasons for replacing the psychological term "alexithymia," no matter how severe the trait, with the neurological label "affective agnosia."

Future research on alexithymia and interoception may help clarify some aspects of the etiology of alexithymia but should not change how the construct is defined. Though the construct of alexithymia could become rei- fied if research evaluating its validity were to cease, it is important that such research retain a close eye on the past and on the extent to which any proposed change to the definition and conceptualization of the construct approximates a trait that is thought to "really" exist in people [8].

\section{Conflict of Interest Statement}

The authors have no conflicts of interest to declare.

\section{Funding Sources}

No external funding was required for this work.

\section{Author Contributions}

Both authors equally contributed to the paper.

\section{References}

1 Nemiah JC, Sifneos PE. Psychosomatic illness: a problem in communication. Psychother Psychosom. 1970;18(1):154-60.

2 Nemiah JC, Sifneos PE. Affect and fantasy in patients with psychosomatic disorders. In: Hill OW, editor. Modern trends in psychosomatic medicine. Volume 2. London: Butterworths; 1970. pp. 26-34.

3 Sifneos PE. The prevalence of 'alexithymic' characteristics in psychosomatic patients. Psychother Psychosom. 1973;22(2):255-62.

4 Ruesch J. The infantile personality. The core problem of psychosomatic medicine. Psychosom Med. 1948 May-Jun;10(3):134-44.

5 Marty P, de M'Uzan M. La 'pensée opératoire’. Rev Fr Psychanal. 1963;27(suppl): 1345-56.

6 Bräutigam W, von Rad M, editors. Toward a theory of psychosomatic disorders. Alexithymia, pensée opératoire, psychosomatisches Phänomen. Proceedings of the 11th European Conference on Psychosomatic Research. Basel: Karger; 1977.

7 Sifneos PE. Comments in panel- and plenum discussion: psychotherapeutic problems with psychosomatic patients. In: Bräutigam W, von Rad M, editors. Toward a theoryof psychosomatic disorders. Alexithymia, pensée opératoire, psychosomatisches Phänomen. Proceedings of the 11th European Conference on Psychosomatic Research. Basel: Karger; 1977. p. 361-75.

8 Loevinger J. Objective tests as instruments of psychological theory. Psychol Rep. 1957; 3(3):635-94.
9 Smith GT. On construct validity: issues of method and measurement. Psychol Assess. 2005 Dec;17(4):396-408.

10 Strauss ME, Smith GT. Construct validity: advances in theory and methodology. Annu Rev Clin Psychol. 2009;5(1):1-25.

11 Clark LA, Watson D. Constructing validity: new developments in creating objective measuring instruments. Psychol Assess. 2019 Dec;31(12):1412-27.

12 Nemiah JC, Freyberger H, Sifneos PE. Alexithymia: a view of the psychosomatic process. In: Hill OW, editor. Modern trends in psychosomatic medicine. Volume 3. London: Butterworths; 1976. pp. 430-9.

13 Apfel RJ, Sifneos PE. Alexithymia: concept and measurement. Psychother Psychosom. 1979;32(1-4):180-90.

14 Taylor GJ, Bagby RM. Measurement of alexithymia. Recommendations for clinical practice and future research. Psychiatr Clin North Am. 1988 Sep;11(3):351-66.

15 Taylor GJ, Ryan D, Bagby RM. Toward the development of a new self-report alexithymia scale. Psychother Psychosom. 1985; 44(4):191-9.

16 Bagby RM, Parker JD, Taylor GJ. The twenty-item Toronto Alexithymia Scale - I. Item selection and cross-validation of the factor structure. J Psychosom Res. 1994 Jan;38(1): 23-32.

17 Bagby RM, Taylor GJ, Parker JD. The Twenty-item Toronto Alexithymia Scale - II. Convergent, discriminant, and concurrent validity. J Psychosom Res. 1994 Jan;38(1): 33-40.
18 Bagby RM, Parker JD, Taylor GJ. Twentyfive years with the 20-item Toronto Alexithymia Scale. J Psychosom Res. 2020 Jan; 131:109940.

19 Bagby RM, Taylor GJ, Parker JD, Dickens SE. The development of the Toronto Structured Interview for Alexithymia: item selection, factor structure, reliability and concurrent validity. Psychother Psychosom. 2006; 75(1):25-39.

20 Taylor GJ, Bagby RM, Parker JD. Disorders of affect regulation. Alexithymia in medical and psychiatric illness. Cambridge, UK: Cambridge University Press; 1997.

21 Taylor GJ, Bagby RM, Ryan DP, Parker JD. Validation of the alexithymia construct: a measurement-based approach. Can J Psychiatry. 1990 May;35(4):290-7.

22 Taylor GJ, Bagby RM. An overview of the alexithymia construct. In: Bar-On R, Parker JD, editors. The handbook of emotional intelligence. San Francisco: Jossey-Bass; 2000. pp. 40-67.

23 Taylor GJ, Bagby RM. Alexithymia and the five-factor model of personality. In: Widiger TA, Costa PT Jr, editors. Personality disorders and the five-factor model of personality. 3rd ed. Washington (DC): American Psychological Association; 2013. pp. 193-207.

24 Grabe HJ, Spitzer C, Freyberger HJ. Alexithymia and the temperament and character model of personality. Psychother Psychosom. 2001 Sep-Oct;70(5):261-7. 
25 Vingerhoets AJ, Van Heck GL, Grim R, Bermond B. Alexithymia: a further exploration of its nomological network. Psychother Psychosom. 1995;64(1):32-42.

26 Vorst HC, Bermond B. Validity and reliability of the Bermond-Vorst Alexithymia Questionnaire. Pers Individ Dif. 2001;30(3): 413-34.

27 Bermond B, Oosterveld P, Vorst HC. Measures of alexithymia. In: Boyle GJ, Saklofske DH, Matthews G, editors. Measures of personality and social psychological constructs. San Diego (CA): Academic Press; 2015. pp. 227-56.

28 Sifneos PE. Problems of psychotherapy of patients with alexithymic characteristics and physical disease. Psychother Psychosom. 1975;26(2):65-70.

29 Damasio A. Looking for Spinoza. Joy, sorrow, and the feeling brain. Orlando (FL): Harcourt; 2003.

30 de Vroege L, Emons WH, Sijtsma K, van der Feltz-Cornelis CM. Psychometric properties of the Bermond-Vorst Alexithymia Questionnaire (BVAQ) in the general population and a clinical population. Front Psychiatry. 2018 Apr;9:111.

31 Bermond B, Clayton K, Liberova A, Luminet O, Maruszewski T, Ricci Bitti P, et al. A cognitive and an affective dimension of alexithymia in six languages and seven populations. Cognit Emot. 2007;21(5):1125-36.

32 Preece D, Becerra R, Allan A, Robinson K, Dandy J. Establishing the theoretical components of alexithymia via factor analysis: introduction and validation of the attention-appraisal model of alexithymia. Pers Individ Dif. 2017;119:341-52.

33 Becerra R, Preece D, Campitelli G, Scott-Pillow $\mathrm{G}$. The assessment of emotional reactivity across negative and positive emotions: development and validation of the Perth Emotional Reactivity Scale (PERS). Assessment. 2019 Jul;26(5):867-79.

34 Preece DA, Becerra R, Robinson K, Allan A, Boyes $\mathrm{M}$, Chen $\mathrm{W}$, et al. What is alexithymia? Using factor analysis to establish its latent structure and relationship with fantasizing and emotional reactivity. J Pers. 2020 Dec;88(6):1162-76.

35 Watters CA, Taylor GJ, Quilty LC, Bagby RM. An examination of the topology and measurement of the alexithymia construct using network analysis. J Pers Assess. 2016 Nov-Dec;98(6):649-59.

36 Bermond B. Brain and alexithymia. In: Vingerhoets A, van Bussel F, Boelhouwer J, editors. The (non) expression of emotions in health and disease. Tilburg: Tilburg University Press; 1996. pp. 115-29.

37 Moormann PP, Bermond B, Vorst HC, Bloemendaal AF, Teijn SM, Rood L. New avenues in alexithymia research: the creation of alexithymia types. In: Vingerhoets A, Nyklicek I, Denollet J, editors. Emotion regulation: conceptual and clinical issues. New York (NY): Springer; 2008. pp. 27-42.
38 Parker JD, Keefer KV, Taylor GJ, Bagby RM. Latent structure of the alexithymia construct: a taxometric investigation. Psychol Assess. 2008 Dec;20(4):385-96.

39 Mattila A, Keefer KV, Taylor GJ, Joukamaa M, Jula A, Parker JD, et al. Taxometric analysis of alexithymia in a general population sample from Finland. Pers Individ Dif. 2010; 49(3):216-21.

40 Keefer KV, Taylor GJ, Parker JD, Bagby RM. Taxometric analysis of the Toronto Structured Interview for Alexithymia: further evidence that alexithymia is a dimensional construct. Assessment. 2019 Apr;26(3): 364-74.

41 Bagby RM, Quilty LC, Taylor GJ, Grabe HJ, Luminet $\mathrm{O}$, Verissimo $\mathrm{R}$, et al. Are there subtypes of alexithymia? Pers Individ Dif. 2009;47(5):413-8.

42 Alkan Härtwig E, Crayen C, Heuser I, Eid M. It's in the mix: psychological distress differs between combinations of alexithymic facets. Front Psychol. 2014 Nov;5:1259.

43 Carnovale M, Taylor GJ, Bagby RM. An evaluation of alexithymia subtypes using latent profile analysis. Manuscript under review.

44 Preece D, Becerra R, Robinson K, Dandy J, Allan A. The psychometric assessment of alexithymia: development and validation of the Perth Alexithymia Questionnaire. Pers Individ Dif. 2018;132:32-44.

45 Watters CA, Taylor GJ, Bagby RM. Illuminating the theoretical components of alexithymia using bifactor modeling and network analysis. Psychol Assess. 2016 Jun; 28(6):627-38.

46 Tibon S, Weinberger Y, Handelzalts JE, Porcelli P. Construct validation of the Rorschach Reality-Fantasy Scale in alexithymia. Psychoanal Psychol. 2005;22(4):508-23.

47 Lane RD, Weihs KL, Herring A, Hishaw A, Smith R. Affective agnosia: expansion of the alexithymia construct and a new opportunity to integrate and extend Freud's legacy. Neurosci Biobehav Rev. 2015 Aug;55:594611.

48 Taylor GJ, Bagby RM, Parker JD. What's in the name 'alexithymia'? A commentary on "Affective agnosia: expansion of the alexithymia construct and a new opportunity to integrate and extend Freud's legacy". Neurosci Biobehav Rev. 2016 Sep;68:1006-20.

49 Sifneos PE. Clinical observations on some patients suffering from a variety of psychosomatic diseases. Acta Med Psychosom. 1967;7:3-10.

50 Sifneos PE. Affect deficit and alexithymia. New Trends Exper Clin Psychiatry. 1994;10: 193-5.

51 Lane RD, Schwartz GE. Levels of emotional awareness: a cognitive-developmental theory and its application to psychopathology. Am J Psychiatry. 1987 Feb;144(2):133-43.
52 Heilman KM, Scholes R, Watson RT. Auditory affective agnosia. Disturbed comprehension of affective speech. J Neurol Neurosurg Psychiatry. 1975 Jan;38(1):69-72.

53 Kurucz J, Feldmar G. Prosopo-affective agnosia as a symptom of cerebral organic disease. J Am Geriatr Soc. 1979 May;27(5):22530.

54 Ricciardi L, Demartini B, Fotopoulou A, Edwards MJ. Alexithymia in neurological disease: a review. J Neuropsychiatry Clin Neurosci. 2015;27(3):179-87.

55 Gross JJ. Emotion regulation: current status and future prospects. Psychol Inq. 2015; 26(1):1-26

56 Taylor GJ, Bagby RM. Psychoanalysis and empirical research: the example of alexithymia. J Am Psychoanal Assoc. 2013 Feb; 61(1):99-133.

57 Preece D, Becerra A, Allan A, Robinson K, Chen W, Hasking P, et al. Assessing alexithymia: psychometric properties of the Perth Alexithymia Questionnaire and 20item Toronto Alexithymia Scale in United States adults. Pers Individ Dif. 2020;166: 110138.

58 Ogrodniczuk JS, Kealy D, Hadjipavlou GA, Cameron K. Therapeutic issues. In: Luminet O, Bagby RM, Taylor GJ, editors. Alexithymia: advances in research, theory, and clinical practice. Cambridge, UK: Cambridge University Press; 2018. pp. 190-206.

59 Taylor GJ. The alexithymia construct: Conceptualization, validation, and relationship with basic dimensions of personality. New Trends Exper Clin Psychiatry. 1994;10(2): 61-74.

60 Smadja C. Psychoanalytic psychosomatics. Int J Psychoanal. 2011 Feb;92(1):221-30.

61 Nemiah JC. The psychodynamic view of anxiety. In: Pasnau RO, editor. Diagnosis and treatment of anxiety disorders. Washington (DC): American Psychiatric Press; 1984. pp. 117-37.

62 Fava GA, Freyberger HJ, Bech P, Christodoulou G, Sensky T, Theorell T, et al. Diagnostic criteria for use in psychosomatic research. Psychother Psychosom. 1995;63(1): $1-8$.

63 Fava GA, Cosci F, Sonino N. Current psychosomatic practice. Psychother Psychosom. 2017;86(1):13-30.

64 Brewer R, Happé F, Cook R, Bird G. Commentary on "Autism, oxytocin and interoception": Alexithymia, not Autism Spectrum Disorders, is the consequence of interoceptive failure. Neurosci Biobehav Rev. 2015 Sep;56:348-53.

65 Brewer R, Cook R, Bird G. Alexithymia: a general deficit of interoception. Roy Soc Open Sci. 2016 Oct;3(10):150664.

66 Taylor GJ. Psychosomatic medicine and contemporary psychoanalysis. Madison (CT): International Universities Press; 1987.

67 Bruch H. Eating disorders: obesity, anorexia nervosa, and the person within. New York: Basic Books; 1973. 
68 Bruch $\mathrm{H}$. The constructive use of ignorance. In: Anthony EJ, editor. Explorations in child psychiatry. New York: Plenum Press; 1975.

69 Garfinkel PE, Garner DM. Anorexia nervosa: a multidimensional perspective. New York: Brunner/Mazel; 1982.

70 Garner DM, Olmstead MP, Polivy J. Development and validation of a multidimensional eating disorder inventory for anorexia nervosa and bulimia. J Eat Disord. 1983; $2(2): 15-34$.

71 Garner DM. Eating Disorder Inventory-2. Odessa (FL): Psychological Assessment Resources Inc; 1991.
72 Taylor GJ, Parker JD, Bagby RM, Bourke MP. Relationships between alexithymia and psychological characteristics associated with eating disorders. J Psychosom Res. 1996 Dec;41(6):561-8.

73 Trevisan DA, Altschuler MR, Bagdasarov A, Carlos C, Duan S, Hamo E, et al. A metaanalysis on the relationship between interoceptive awareness and alexithymia: distinguishing interoceptive accuracy and sensibility. J Abnorm Psychol. 2019 Nov;128(8): 765-76.

74 Cameron OG. Interoception: the inside story - a model for psychosomatic processes. Psychosom Med. 2001 Sep-Oct;63(5):697710.
75 Pollatos O, Herbert BM. Alexithymia and body awareness. In: Luminet O, Bagby RM, Taylor GJ, editors. Alexithymia: advances in research, theory, and clinical practice. Cambridge, UK: Cambridge University Press; 2018. pp. 321-34.

76 Herbert BM, Herbert C, Pollatos O. On the relationship between interoceptive awareness and alexithymia: is interoceptive awareness related to emotional awareness? J Pers. 2011 Oct;79(5):1149-75.

77 Nicholson TM, Williams DM, Grainger C, Christensen JF, Calvo-Merino B, Gaigg SB. Interoceptive impairments do not lie at the heart of autism or alexithymia. J Abnorm Psychol. 2018 Aug;127(6):612-22. 